\title{
Basic Electrical Welding / Electric Welding Training In Laboratory Of Education EngineERING University Of Palangka Raya
}

\author{
Pelatihan Dasar Las Busur Listrik/Las Listrik \\ Di Laboratarium Pendidikan Teknik Mesin \\ Universitas Palangka Raya
}

\author{
Wiyogo $^{1)}$, Fritman Dalito ${ }^{2)}$ \\ ${ }^{1)}$ Program Studi Pendidikan Teknik Mesin, FKIP Universitas Palangka Raya \\ ${ }^{2)}$ Program Studi Pendidikan Teknik Mesin, FKIP Universitas Palangka Raya \\ Kampus Unpar Tunjung Nyaho, Jl. H. Timang, 73111A
}

Email: wiyogo@fkip.upr.ac.id

\begin{abstract}
The training activities are very important because they are useful to increase knowledge or skills, especially for those who are preparing to enter the workforce. Whereas those who are already working will aim to keep the capability maintained. To carry out these activities carried out at the Laboratory of Mechanical Engineering Education Faculty of Teacher Training and Education, University of Palangka Raya. Through community service activities carried out in Higher Education in line with the functions and objectives mandated in Law Number 12 of 2012 Article 4 paragraph 3; "Developing Science and Technology by paying attention and applying the value of Humanities". And in article 5, paragraph 4; "The realization of Community Service based on reasoning and research work that is useful in advancing public welfare and intellectual life of the nation". Through this activity, participants are expected to have basic knowledge about welding electric welding. The method used is like a lecture with presentation techniques, guided direct practice and evaluation.
\end{abstract}

Keywords: Training, Welding, Mechanical Engineering Education

\begin{abstract}
ABSTRAK
Kegiatan pelatihan sangat penting karena bermanfaat guna menambah pengetahuan atau keterampilan terutama bagi yang mempersiapkan diri memasuki lapangan pekerjaan. Sedangkan bagi yang sudah bekerja akan bertujuan agar kapabilitas selalu terjaga. Untuk melaksanakan kegiatan tersebut dilakukan di Laboratarium Pendidikan Teknik Mesin Fakultas Keguruan dan Ilmu Pendidikan Universitas Palangka Raya. Melalui kegiatan pengabdian kepada masyarakat yang dilaksanakan di Perguruan Tinggi sejalan dengan fungsi dan tujuan yang diamanatkan dalam Undang - Undang Nomor 12 Tahun 2012 Pasal 4 ayat 3; "Mengembangkan Ilmu Pengetahuan dan Teknologi dengan memperhatikan dan menerapkan nilai Humaniora". Dan pada pasal 5 ayat 4; "Terwujudnya Pengabdian kepada Masyarakat berbasis penalaran dan karya Penelitian yang bermanfaat dalam memajukan kesejahteraan umum dan mencerdaskan kehidupan bangsa". Melalui kegiatan ini, diharapkan peserta dapat memiliki pengetahuan dasar mengenai pengelasan las listrik. Adapun metode yang digunakan adalah seperti ceramah dengan teknik presentasi, praktik langsung terbimbing dan evaluasi.
\end{abstract}

Kata Kunci: Pelatihan, Pengelasan, Pendidikan Teknik Mesin

\section{PENDAHULUAN}

Semakin banyaknya pengangguran dikalangan usia muda produktif, semakin menunjukkan bahwa ketersediaan lapangan kerja yang sangat terbatas. Hal tersebut tentu saja disebabkan oleh banyak faktor yang sangat kompleks. Salah satu solusi yang sangat realistis untuk diwujudkan adalah melalui usaha peningkatan jumlah wirausaha terutama dikalangan muda produktif. Berdasarkan data statistik sampai bulan Mei 2017, di Kalimantan Tengah jumlah pengangguran sebesar Tingkat
Pengangguran sebesar $3,13 \%$ dari jumlah penduduk sebesar 1.327.871.

Jumlah penganggur mencapai 42.895 orang dengan Tingkat Partisipasi Angkatan Kerja (TPAK) sebesar 2,67 poin. Untuk Tingkat Pengangguran Terbuka (TPT), lulusan SMA (SMA/SMK) menempati posisi teratas sebesar 5,33\% kemudian disusul oleh lulusan Perguruan Tinggi sebesar 3,60 \%. Badan Pusat Statistik Provinsi Kalimantan Tengah juga melaporkan jumlah tentang penduduk usia 15 tahun ke atas yang bekerja menurut Lapangan Pekerjaan Utama 
dan Kabupaten/Kota di Kalimantan Tengah tahun 2014. Jumlah peminat kerja di sektor jasa yang banyak dari sektor lainnya, sebanyak 168.817 dari 1.154.489 tenaga kerja yang ada (Sumber: http://kalteng.bps.go.id/linkTableDinamis/view/id/25,

diakses tanggl 5 Mei 2017). Peluang kerja dibidang jasa memiliki kesempatan yang terbuka luas bagi pencari kerja.

Semakin banyaknya pengangguran di kalangan usia muda produktif, semakin menunjukkan bahwa ketersediaan lapangan kerja yang sangat terbatas. Hal tersebut tentu saja disebabkan oleh banyak faktor yang sangat kompleks. Namun demikian, salah satu solusi yang sangat realistis untuk diwujudkan adalahmelalui usaha peningkatan jumlah wirausaha terutama dikalangan muda produktif.

Solusi mengatasi pengangguran bukan hanya merupakan tugas pemerintah, tetapi hal tersebut harus didukung oleh semua masyarakat, seperti misalnya Perguruan Tinggi dalam hal ini Dosen masih belum maksimal ikut serta dalam pemberdayaan masyarakat. Solusi yang dapat diberikan adalah melalui kegiatan pelatihan - pelatihan keahlian. Kegiatan pelatihan tersebut bertujuan menjadikan peserta mampu berwirausaha. Sasaran pelatihan yang strategis adalah kelompok siswa lulusan SMA/SMK yang belum mendapatkan pekerjaan secara tetap. Bidang usaha produktif yang dipilih dalam kegiatan Program Pengembangan Usaha Intelektual Kampus (PUPIK) FKIP UPR 2017 adalah bidang las listrik. Bidang las sangat potensial untuk langsung dijadikan wirausaha baru dibidang jasa.

\section{METODE PELAKSANAAN}

Melalui kegiatan PUPIK yang dilaksanakan di Perguruan Tinggi Mengembangkan Ilmu Pengetahuan dan Teknologi dengan diharapkan mampu memperhatikan dan menerapkan nilai Humaniora, Terwujudnya Pengabdian kepada Masyarakat berbasis penalaran dan karya Penelitian yang bermanfaat dalam memajukan kesejahteraan umum dan mencerdaskan kehidupan bangsa dan bagi peserta memperoleh pengetahuan dasar mengenai pengelasan dasar las listrik.

\subsection{Langkah - Langkah Kegiatan}

Langkah-langkah yang dilakukan dalam melaksanakan pelatihan agar berjalan sukses yaitu sebagai berikut:

1. Menganalisis kebutuhan peserta pelatihan pengelasan dasar, atau yang disebut need analysis atau need assessment.

2. Menentukan sasaran dan materi program pelatihan pengelasan dasar

3. Menentukan metode pelatihan dan prinsip-prinsip belajar yang digunakan pada pelatihan pengelasan dasar.
Adapun metode yang digunakan adalah seperti ceramah dengan teknik presentasi, praktik langsung terbimbing (pengenalan dasar las listrik, keselamatan kerja dan pembuatan produk) dan evaluasi.

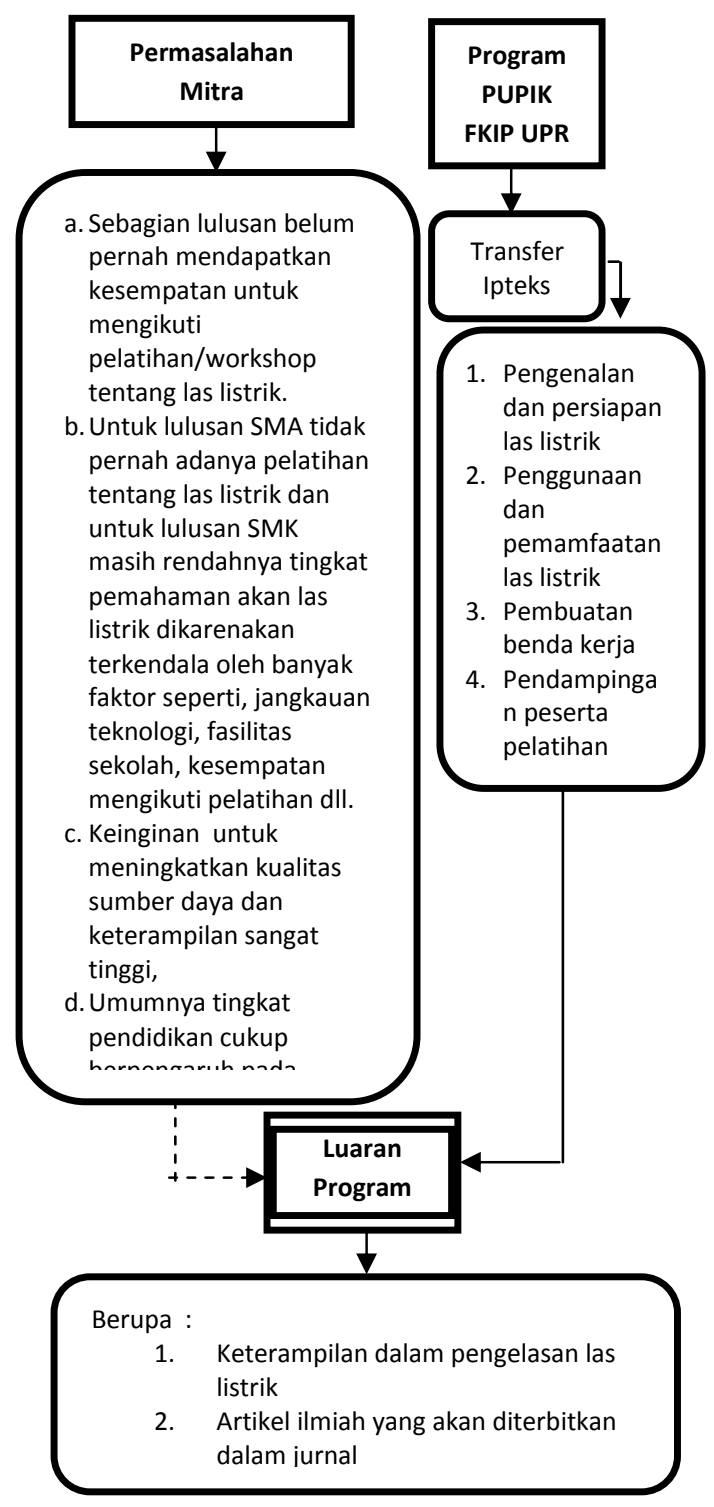

Gambar 1. Desain mengatasi permasalahan mitra

4. Mengevaluasi program kegiatan.

\section{Hasil Pelaksanaan Kegiatan}

Hasil kegiatan pengabdian ini merupakan jawaban dari sebuah rencana luaran yang ingin dicapai adapun luaran tersebut :

1. Kegiatan peserta pelatihan dalam pengelasan dasar yaitu sebagai berikut :

a. Pengarahan dan Perencanaan Pengelasan

Prosedur pengelasan akan memberikan hasil yang baik bila sebelumnya telah dibuat rencana tentang jadwal pembuatan, persiapan pengelasan, perlakuan setelah 
pengelasan, pengaturan pekerjaan dan lain - lain. Berdasarkan rencana kontruksi biasanya dibuat penjadwalan secara menyeluruh dengan mempelajari urutan perakitan, banyaknya pekerjaan las yang diperluakan, kapasitas dari alat alat yang ada, kerja yang diperlukan dan sebagainya.
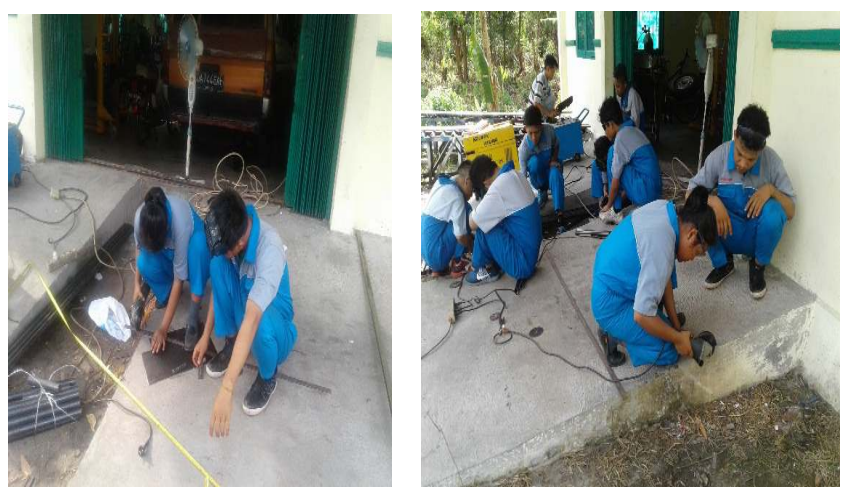

Gambar 2. Pelaksanaan Kegiatan

Dalam memilih proses pengelasan harus dititk beratkan pada proses yang paling sesuai untuk tiap- tiap sambungan las yang ada pada kontruksi. Dalam hal ini tentu dasarnya adalah efisiensi yang tinggi, biaya yang murah, penghematan tenaga dan penghematan energi sejauh mungkin. Proses pengelasan yang dipilih harus sudah ditentukan dalam tahap perencanaan kontruksi. Bila proses pengelasan telah ditentukan untuk tiap-tiap sambungan, maka tahap berikutnya adalah menentukan syaratsyarat pengelasan, urutan pengelasan dan persiapan pengelasan. Baru setelah itu harus di tentukan cara-cara menghilangkan deformasi dan laku panas yang diperlukan

b. Peserta pelatihan mampu mempersiapkan bahan dan alat dalam pelaksanaan pengelasan.

Persiapan sisi las merupakan langkah awal yang perlu dilakukan. Langkah ini disesuaikan dengan perencanaan pengelasan. Setelah dilakukan penentuan proses pengelasan, maka geometri sambungan harus ditentukan dengan memperhatikan dengan tingkatan teknik dari bagian pembuatan, sifat kemampuan pengerjaannya dan kemungkinan penghematan yang akhirnya tertuju pada bentuk alur dari pengelasan. Hal - hal utama yang dipersiapkan pada pengelsan tingkat dasar adalah:

1) Peralatan utama:

-Alat las busur listrik

- Arus listrik

- Kabel elektroda

-Kabel massa

-Kabel tenaga
2) Peralatan bantu :

-Tang

- Mesin gerinda

-Sikat baja

- Meja las

- Palu kerak

3) Peralatan keselamatan :

- Topeng las

- Masker hisap

- Pelindung dada/Baju Kerja

- Sarung tangan

-Sepatu keselamatan

1. Langkah-langkah Pelaksanaan Kegiatan, yaitu :

1. Mempersiapkan bahan dengan mengukur potongan/bagian - bagian logam yang akan di las, kemudian dilanjutkan dengan tindakan mengelas dengan benda kerja yang paling sederhana terlebih dahulu.

2. Bersikap tenang dan rileks serta tempatkan badan pada posisi yang senyaman mungkin.

3. Mengatur posisi kemiringan elektroda terhadap benda kerja tersebut, ideal kemiringa elektroda yaitu 70 derajat atau 80 derajat.

4. Melaksanakan pengelasan. Arahkan pengelasan mengikuti arah kemiringan elektroda menggores. Usahakan rigi-rigi yang akan dilas tetap dalam keadaan yang lurus pada jalurnya.

5. Tiga sikap dasar yang harus dimiliki pada saat mengelas yaitu ketenangan, ketelitian, dan keuletan. Semua pekerjaan harus dilakukan dengan hati-hati. Tidak masalah apakah pekerjaan tersebut memakan waktu yang lebih lama, tetapi yang paling penting ialah hasilnya kuat dan rapi. Hindari bekerja dengan perasaan 
yang terburu-buru ingin segera menyelesaikannya.

\subsection{Transfer Ipteks}

Dalam pelaksanaan kegiatan dilakukan upaya pemecahan masalah dan strategi pemberdayaan masyarakat dengan meningkatkan potensi pemuda/peserta dalam meningkatkan pendapatan melalui pelatihan Dasr las listrik . Gambaran secara umum yang akan dilakukan adalah :

1. Perencanaan Konstruksi Las;

- Persiapan pengelasan dan hal - hal umum persiapan pengelasan.

- Klasifikasi sambungan las dan bentuk alur ampuh las, seperti kekuatan sambungan las, mekanisme patah perubahan bentuk atau deformasi las dan tegangan sisa dalam lasan.

- Pemilihan bahan dan penghindaran cacat las juga dibahas dan dihubungkan dengan prosedur dan perencanaan pengelasan.

\section{Klasifikasi sambungan las}

- Sambungan Las Dasar; sambungan las dalam kontruksi baja pada dasarnya dibagi dalam sambungan tumpul, sambungan $T$, sambungan sudut dan sambungan tumpang, sambungan dengan penguat dan sambungan sisi.

- Sambungan Tumpul; Sambungan tumpul adalah jenis sambunganyang paling efesien, sambungan ini dibagi lagi dalam dua yaitu sambungan penetrasi penuh dan sambungan penetrasi menjadi sambungan tanpa pelat pembantu yang masih dibagi lagi dalam pelat pembantu yang turut menjadi bagian dari kontruksi dan pelat pembantu yang hanya sebagai penolong pada waktu proses pengelasan saja.

- Sambungan dan jaminan sambungan.

- Bentuk-bentuk yang telah distandarkan pada umumnya hanya meliputi pelaksanaan pengelasan yang sering dilakukan sehingga dalam pengelasan khusus bentuk alur harus ditentukan sendiri berdasarkan penglaman yang dapat dipercaya.

3. Sambungan bentuk T dan silang;

Pada kedua sambungan ini secara garis besar dibagi dalam dua jenis yaitu jenis las, dengan alur dan jenis las sudut, hal-hal yang dijelaskan untuk sambungan tumpul diatas juga berlaku untuk sambungan jenis ini, dalam pelaksanaan pengelasan mungkin sekali ada bagian batang yang menghalngi yang dalam hal ini dapat diatasi dengan memperbesar sudut alur.
- Sambungan sudut; Dalam sambungan ini dapat terjadi penyusunan dalam arah tebal pelat yang dapat menyebabkan terjadinya retak lamel, hal ini dapat dihindari dengan membuat alur pada pelat tegak seperti yang terlihat dalam pengelasan yang tidak dapat dilakukan karena sempitnya ruang maka pelaksanaanya dapat dilakukan dengan pengelasan tembus atau pengelasan dengan pelat pembantu.

- Sambungan Tumpang; Sambungan tumpang dibagi dalam 3 jenis. Karena sambungan ini efisiensinya rendah maka jarang sekali digunakan untuk pelaksanaan penyambungan konstruksi utama. Sambungan tumpang biasanya dilaksanakan dengan las sudut, dan las isi.

- Sambungan sisi; Sambungan sisi dibagi dalam sambungan las dengan alur dan sambungan las ujung. Untuk jenis yang pertama pada pelatnya harus dibuat alur sedangkan pada jenis kedua pengelasan dilakukan pada ujung pelat tanpa ada alur. Jenis kedua ini biasanya hasilnya kurang memuaskan kecuali bila pengelasannya dilakukan dalam posisi datar dengan aliran listrik yang tinggi.

- Sambungan dengan pelat penguat; Sambungan ini dibagi dalam dua jenis yaitu sambungan dengan pelat penguat tunggal dan dengan pelat penguat ganda. Sambungan ini mirip dengan sambungan tumpang. Dengan alasan yang sama dengan sambungan tumpang, maka sambungan ini pun jarang digunakan untuk penyambungan konstruksi utama.

\subsection{Hasil Luaran Kegiatan}

Peserta pelatihan mampu melaksanakan pengelasan jalur. Proses pengelasan dibagi dalam dua katagori utama, yaitu pengelasan lebur dan pengelasan padat. Pengelasan lebur menggunakan panas untuk melebur permukaan yang akan disambung, beberapa operasi menggunakan logam pengisi dan yang lain tanpa logam pengisi. Pengelasan padat proses penyambungannya menggunakan panas dan/atau tekanan, tetapi tidak terjadi peleburan pada logam dasar dan tanpa penambahan logam pengisi.

\section{Gambar 3. Posisi Badan Saat Pegelasan}

Posisi pengelasan yang terbaik dilihat dari hasil sambungan dan efisiensi pengelasan yang pas adalah dengan posisi datar. Dalam menentukan urutan perakitan, landasan perakitan dan alat perakit harus mengusahakan sejauh mungkin menggunakan posisi datar. 


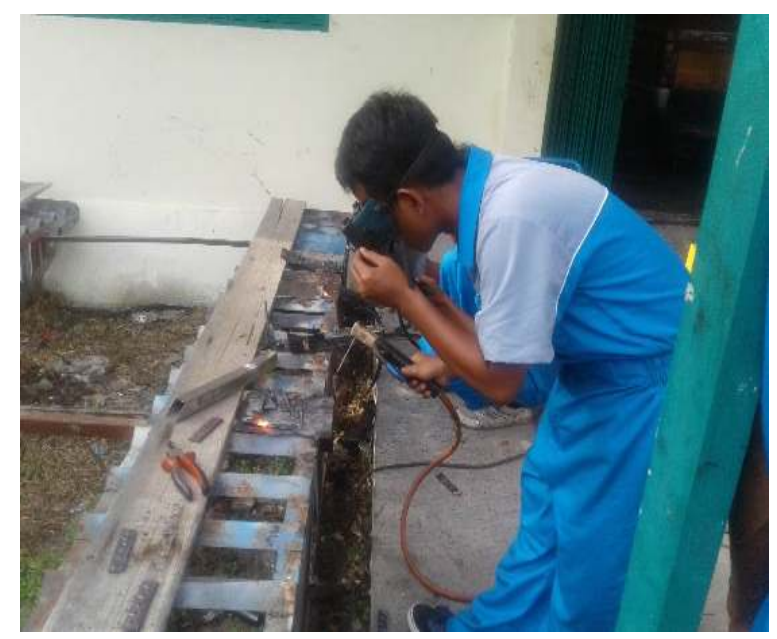

Gambar 4. Penggunaan Kacamata Las sebagai Alat Keselamatan Kerja

Adapun 3 (Tiga) hal keterampilan peserta pelatihan dalam dasar pengelasan, yaitu:

1. Peserta memiliki pengetahuan dan pengenalan macam-macam peralatan las listrik.

2. Peserta mampu menyetel nyala las listrik sesuai dengan jenis elektrode yang dipakai.

3. Memakai/menggunakan alat las dan mampu membuat benda kerja menggunakan las listrik.

\section{PENUTUP}

\subsection{Kesimpulan}

Pelatihan teknik dasar pengelasan telah dilaksanakan dengan baik, setelah terlaksananya program ini, diperoleh solusi dari permasalahan mereka yaitu peserta memiliki pengetahuan yang cukup. Kemampuan pengelasan dasar akan semakin berkembang asalkan mereka mau mengembangkan diri sesuai contoh yang telah diberikan. Harapan dan saran tim pengabdian semoga pada waktu mendatang, tim pengabdian dapat membantu peserta pelatihan lagi, untuk mencari solusi tentang kesulitan yang mereka hadapi saat melaksanakan pengelasan selanjutnya.

\subsection{Saran}

Proses pengelasan memerlukan lebih banyak ujicoba dan keberanian dalam mengasah ilmu yang telah diperoleh saat pelatihan, maka dari itu disarankan kepada semua peserta pelatihan untuk lebih percaya diri dan tidak malu untuk bertanya kepada instuktur pelaksana pelatihan walaupun diluar kegiatan pelatihan serta disarankan selalu menggunakan peralatan pelindung.

\section{DAFTAR PUSTAKA}

[1]. Badan Pusat Statistik Provinsi Kalimantan Tengah. 2015. Jumlah Penduduk usia 15 tahun ke atas yang bekerja menurut Lapangan Pekerjaan Utama dan Kabupaten/Kota di Kalimantan Tengah tahun 2014 (http://kalteng.bps.go.id/linkTableDinamis/view/id/ 25, diakses pada 5 Mei 2017).

[2]. Badan Pusat Statistik Provinsi Kalimantan Tengah Tahun 2017. Tingkat Pertumbuhan Sepeda Motor pada Tahun 2014

(http://kalteng.bps.go.id/linkTableStatis/view/id/22, daikses tanggal 4 Juni 217).

[3]. Badan Pusat Statistik Provinsi Kalimantan Tengah. 2017.Tingkat Pengangguran Terbuka (TPT) sampai dengan Bulan Mei Tahun 2017 (http://kalteng.bps.go.id/index.php/brs/654, diakses pada 5 Mei 2017)

[4]. Dinas Tenaga Kerja dan Transmigrasi Provinsi Kalimantan Tengah. 2017. Pencari Kerja Yang Terdaftar menurut Kabupaten/Kota di Provinsi Kalimantan Tengah tahun 2015. Pelangka Raya: http://kalteng.bps.go.id/linkTabelStatis/view/id/277, diakses pada 5 Juni 2017). 